\title{
JOSÉ CONSUEGRA HIGGINS: ABANDERADO DEL PENSAMIENTO PROPIO
} JOSÉ CONSUEGRA HIGGINS: PROMOTER OF A LATIN AMERICAN WAY OF THINKING

\section{JOSÉ CONSUEGRA HIGGINS: PROMOTOR DO PENSAMENTO PROPRIO}

Conferencia dictada en la sexta versión de la Cátedra América Latina José Consuegra Higgins, 11, 12 y 13 de noviembre de 2015.

\author{
Por Julián Sabogal Tamayo
}

Profesor Titular y Profesor Emérito de la Universidad de Nariño, Doctor Honoris Causa de la Universidad Simón Bolívar, Miembro de Número de la Academia Colombiana de Ciencias Económicas, autor de nueve libros y coautor de otros nueve.E-MAIL: sabogaleconomia@gmail.com

\section{RESUMEN}

Me propongo reflexionar sobre los aportes teóricos del maestro José Consuegra Higgins, en su trasegar intelectual en la defensa del pensamiento propio. Me centraré en tres temas fundamentales: primero, una introducción general sobre la importancia del pensamiento del maestro Consuegra Higgins, su defensa del pensamiento latinoamericano y del pensamiento propio; segundo, la importancia del Pensamiento Propio en la situación actual del mundo y, tercero, los aportes del maestro Consuegra a las tareas actuales del pensamiento de las ciencias sociales.

\section{ABSTRACT}

I intend to meditate on the teacher's theoretical contributions of José Consuegra Higgins, in his intellectual work in defense of the Latin American Thought and the Own Thought. Especially about three fundamental topics: first, a general introduction about the importance of the José Consuegra Higgins's thought; second, the importance of the Own Thought in the current situation of the world and, third, the contributions of the teachings of Consuegra to the actual social sciences.

\section{RESUMO}

Me proponho refletir sobre as contribuições teóricas do mestre José Consuegra Higgins, em sua trajetória intelectual na defesa do pensamento próprio. Vou me concentrar em três questões fundamentais: primeiro, a introdução geral sobre a importância do pensamento do mestre Consuegra Higgins, sua defesa do pensamento latino-americano e do pensamento próprio; segundo, a importância do Pensamento Próprio na situação atual do mundo e, terceiro, as contribuições do mestre Consuegra às tarefas atuais do pensamento das ciências sociais. 
Quiero, ante todo, agradecer la oportunidad de participar en la sexta versión de la Cátedra América Latina - José Consuegra Higgins, a la cual me he sentido especialmente vinculado tanto intelectual como emocionalmente; en esta oportunidad me es particularmente cara esta participación por la conmemoración de los 50 años de Desarrollo Indoamericano, revista a la cual he estado siempre vinculado, primero como lector y después, además, como columnista. En esta conferencia trataré tres temas fundamentales: primero, una introducción general sobre la importancia del pensamiento del maestro Consuegra Higgins; segundo, la importancia del Pensamiento Propio en la situación actual del mundo y, tercero, los aportes del maestro Consuegra a las tareas actuales del pensamiento de las ciencias sociales.

\section{INTRODUCCIÓN}

Como escribí en mi libro sobre el maestro:

Consuegra, en su ya larga vida transcurrida entre la escritura, la lectura, las aulas y el ejercicio de la política ha tenido un solo horizonte: aportar al pensamiento propio. En ese empeño, ha desatado estrategias en variadas direcciones. Ha escrito muchos libros, de economía, de historia, de política, de pensamiento, de recuerdos personales; ha prologado los libros de sus amigos, que son muchísimos particularmente a lo largo y ancho de América Latina; ha recomendado la publicación de libros, en editoriales en las que goza de mucha autoridad; fundó una universidad, con el nombre de quien considera el más grande de los latinoamericanos, simón Bolívar; creó la revista Desarrollo Indoamericano, en la que a lo largo de los últimos cuarenta años ha desfilado una parte importante del pensamiento económico y social de América Latina (Sabogal, 2007: 29-30).

El maestro Consuegra Higgins que ha sido siempre un defensor y difusor del Pensamiento Latinoamericano, nos obliga, hoy más que nunca, a darle vida a su pensamiento. En ese sentido, me propongo mostrar algunos aspectos de sus enseñanzas teóricas. No me detendré, esta vez, en otros aspectos de su magisterio como publicador de libros de pensadores latinoamericanos, organizador y creador de instituciones educativas, etc., algunos de estos aportes se describen en mi libro que lleva el mismo nombre de esta conferencia.

Me considero un conocedor de la obra teórica de Consuegra Higgins, lo que no significa que ese conocimiento esté agotado. Es necesario continuar estudiando su obra y confrontándola con las nuevas realidades sociales y económicas; esto me propongo hacer en esta conferencia. No olvidemos que el dominio de la cuasi religión neoliberal llevó a expulsar de la docencia de las ciencias sociales, sobre todo el pensamiento propio; la enseñanza de la Economía, en general, en las últimas décadas se ha dedicado a repetir dogmáticamente las consignas de competitividad y de mercado libre elaboradas en los centros de poder, particularmente en los organismos financieros tipo Banco Mundial, Fondo Monetario Internacional y Organización Mundial de Comercio. Contra esa repetición dogmática luchó siempre el maestro Consuegra. El olvido de lo nuestro es de tales dimensiones que, por ejemplo, la organización que agrupa a las carreras de Economía en Colombia, 
AFADECO, ignoró el centenario del nacimiento de Antonio García Nossa, en el año 2012, siendo este pensador el padre de la carrera de Economía en nuestro país.

Los momentos de grandes crisis van siempre acompañados de virajes teóricos, de crisis del pensamiento dominante. El Premio Nobel de Economía de 1981 James Tobin decía: "son los grandes eventos los que desacreditan determinadas ideas y promueven su sustitución por otras nuevas". En uno de esos momentos nos encontramos hoy en el mundo. La crisis sistémica en la que se debate el mundo, está poniendo en entredicho el pensamiento único neoliberal y el único camino que tenemos es la creación de ciencias sociales alternativas, novedosas. Y aquí el maestro Consuegra debe tomar nuevamente la palabra, lograr que pueda hacerlo es nuestra tarea; a eso estoy invitando a los colegas y a los estudiantes de esta prestigiosa Universidad.

Esto debe ser hecho con entereza, sin complejos de inferioridad, como lo hacía Consuegra y como lo hizo también su maestro: Antonio García Nossa. Para tomar un solo ejemplo de la independencia del maestro Consuegra, recordemos que cuando emprendió la titánica tarea de editar las obras de los principales pensadores latinoamericanos, en la Antología de Pensamiento Económico y Social de América Latina, APESAL, la casa matriz de la editorial planteó que ellos debían revisar los textos para darles su aprobación, lo cual fue rechazado de manera contundente por el maestro; él lo cuenta de esta manera:

Un día fui informado de que los jerarcas de Barcelona exigían el envío de los originales para estudiarlos previamente y emitir conceptos sobre su posible impresión. Entonces, por conducto del tratadista de Derecho Civil, doctor Arturo Valencia Zea, y de la poetisa Lucía Muelle, gerente de dicha casa editora en Colombia, les hice saber que en mi condición de economista y catedrático no sabía de ningún español que tuviese autoridad científica para calificar o censurar la obra de Raúl Prebisch, José Carlos Mariátegui, Josué de Castro, Celso Furtado, José Ingenieros, Antonio García, Alonso Aguilar, D.F. Maza Zavala, etc., porque apenas, en la etapa mercantilista del siglo XVII, algunos autores de ese país ofrecieron sus aportes a las doctrinas económicas. La sugerencia de los modernos inquisidores fue tan absurda que condujo a la protesta y al retiro de la señora Muelle (Consuegra, 2002: 182).

\section{EL PENSAMIENTO PROPIO Y LA CRISIS}

Hoy, más que antes, se precisa un pensamiento propio en América Latina, no solo para entenderse a sí misma sino para entender al mundo. El Sistema-mundo capitalista se encuentra en medio de una crisis sistémica que, además del componente económico, tiene el componente ambiental, las expulsiones, el hambre y una crisis de valores; es una verdadera crisis civilizatoria, es la civilización de la modernidad la que ha entrado en crisis, como dice el pensador egipcio Samir Amín: El principio de la acumulación sin fin que define al capitalismo es sinónimo de crecimiento exponencial, y éste, como el cáncer, lleva a la muerte (Amin, 2009: 1).

Me detendré someramente en los componentes de la crisis distintos al económico, porque este es el más conocido. En primer lugar me refiero al problema ambien- 
tal. Este tiene que ver fundamentalmente con la contradicción insoluble existente entre el crecimiento infinito de la producción y el carácter finito del planeta; como dijo el economista K. Boulding: Quien crea que el crecimiento exponencial puede durar eternamente en un mundo finito, o es un loco o es un economista.

Entre los componentes del problema ambiental está el cambio climático, causado por las emisiones de $\mathrm{CO}_{2}$ Anualmente se producen unas 25.000.000.000 de toneladas de bióxido de carbono, que van a la atmósfera. Se calcula que en el año 2100 habrá entre 541 y 970 ppm de $\mathrm{CO}_{2}$ en la atmósfera (hoy 400 ppm); esto hará que la temperatura del planeta suba entre $4-7^{\circ} \mathrm{C}$. Por supuesto, los países que más $\mathrm{CO}_{2}$ producen son los más industrializados; Estados Unidos produce el 25\% del $\mathrm{CO}_{2}$ del mundo, siendo su población el 4\%, China produce el 14\%, Colombia produce solo el $0.2 \%$ del $\mathrm{CO}_{2}$ pero los efectos los recibimos todos por igual. La producción de $\mathrm{CO}_{2}$ tiene que ver con el consumo de combustibles fósiles, petróleo y carbón. Este problema tiene una historia reciente, de menos de 250 años, desde la Revolución Industrial. Pero cada vez se agudiza más con el comercio internacional, que agrava la ruptura del metabolismo social. Tomemos el ejemplo del maíz, Colombia está importando el 75\% del maíz que consumimos, un producto que se puede producir en el país, es decir, cerca del lugar de consumo y con ello ahorrar el petróleo del transporte y, por lo tanto, disminuir las emisiones de $\mathrm{CO}_{2}$. Esto no se hace así, porque los Tratados de Libre Comercio dejan más ganancias a las grandes empresas transnacionales, al tiempo que destruyen la producción agraria e industrial de los países menos desarrollados, como ha sucedido con Colombia.

La desigualdad en la distribución del ingreso y la riqueza tiende a crecer. Un libro de reciente aparición, que se puso de moda en el mundo, titulado El capital en el siglo XXI, del Economista francés Thomas Piketty, demuestra con una cantidad monumental de datos estadísticos desde el siglo XVIII hasta el XXI, que la tendencia es hacia una desigualdad cada vez mayor, y los países más desarrollados serán aún más desiguales que el promedio; las proyecciones de Piketty para Estados Unidos dicen que este país en 2030 tendrá un Coeficiente de Gini muy cercano a $0.6^{\mathbf{1}}$. El Global Wealth Report 2015 dice que los más ricos del mundo que constituyen el 0.7\% de la población mundial son dueños del 45,2\% de la riqueza del planeta; por su parte Saskia Sassen, en su libro Expulsiones. Brutalidad y complejidad en la Economía Global nos dice que ha habido un aumento del 60 por ciento en la riqueza del uno por ciento más rico a nivel global; en la cima de ese uno por ciento, los más ricos agregaron 240.000 millones de dólares a su riqueza en 2012, lo suficiente para terminar con la pobreza del mundo cuatro veces ${ }^{2}$.

Hay un fenómeno relativamente nuevo en el sistema que son las expulsiones. Algunas poblaciones siempre han sido expulsadas de sus territorios, pero lo nuevo es que el modelo imperante mismo, con sus propias reglas, está expulsando gente. Hoy en día, muchas personas que pierden su empleo no lo vuelven a recuperar en su vida, son expulsados del sistema, al respecto nos dice Bauman, lo siguiente:

1. Cf. PIKETTY, Thomas (2014). El capital en el siglo XXI, Bogotá: Fondo de Cultura Económica, p. 273.

2. Cf. SASSEN, Saskia (2015). Expulsiones. Brutalidad y complejidad en la Economía Global, Bogotá: Kats editores, p. 24. 
Antes la prueba de fuego de una buena sociedad consistía en puestos para todos y un papel productivo para cada uno. El prefijo “des”, en "desempleo”, solía sugerir una salida de la norma. Nada semejante sugiere el concepto de "superfluidad". Ningún indicio de anormalidad. Que te declaren superfluo significa haber sido desechado por ser desechable.

La "población excedente” es una variedad más de residuos humanos. ...las "vidas indignas de ser vividas", las víctimas de los diseños de construcción del orden, no son "blancos legítimos"... Se trata más bien de "víctimas colaterales” del progreso económico, imprevistas y no deseadas (Bauman, 2006: 57).

Sassen enumera varios métodos de expulsión, como los siguientes. Con la llegada del Neoliberalismo y la consiguiente eliminación del llamado Estado del Bienestar, los trabajadores de bajos salarios y los desempleados fueron expulsados de los programas gubernamentales de salud y bienestar social; el uso del fracking en la minería transforma ambientes naturales en tierras muertas, expulsando a sus habitantes; la burbuja inmobiliaria, lanzó a la calle a los deudores hipotecarios igual en Estados Unidos que en Europa; la compra de tierras por parte de grandes empresas en los países de la periferia, expulsa a los campesinos que las ocupaban ${ }^{3}$.

Los valores propios del mercado están en crisis. No me refiero a valores como la ética; el capital no tiene ética, como lo sostuvo Marx y lo ha estudiado abundantemente el Filósofo latinoamericano Enrique Dussel, pero son los valores que defienden los propios capitalistas los que están en crisis. El protagonista de la novela de Jorge Volpi, Memorial del engaño, dice que en Wall Street todos son dignos alumnos de Carlo Ponzi. Basten un par de ejemplos: un respetable empresario de Wall Street, Bernard Madoff, creó una pirámide que fue descubierta en 2008 con la cual defraudó a miles de inversionistas en una suma de alrededor de 65.000 millones de dólares; el robo más grade de la historia, llevado a cabo por una sola persona. Recientemente se descubrió el fraude de la empresa de automóviles Volkswagen con una manipulación del software que informa sobre las emisiones de carbono de los carros, para que indicara una cantidad menor de la realmente emitida, lo que no es óbice para que los empresarios se sigan declarando defensores del ambiente limpio.

\section{LO QUE APORTA JOSÉ CONSUEGRA HIGGINS A LA REALIDAD ACTUAL}

Este panorama global implica una gran responsabilidad teórica para quienes somos trabajadores de las ciencias sociales, en la actualidad.

Ya hablamos de la crisis mundial, que implica también una crisis de la ciencia económica. En el ámbito nacional tenemos un reto, no menos importante, ante la firma inminente del fin de la guerra entre el Estado colombiano y la guerrilla de las FARC. Firmado ese acuerdo queda la gran tarea de tejer la paz en los territorios, lo cual implica una gran tarea teórica.

En la elaboración teórica, tanto para enfrentar los retos globales como los nacionales, el pensamiento propio que nos dejó el maestro Consuegra Higgins tiene

3. Cf. SASSEN, Saskia, Op. cit., pp. 12-13. 
mucho que aportar. Daré a continuación solo unos ejemplos, particularmente en lo que tiene que ver con Colombia y Latinoamérica de lo que podemos aprender del maestro.

Sobre la paz, el maestro escribió, mientras se adelantaban conversaciones entre el Gobierno de Belisario Betancur, en los años ochenta, lo siguiente:

La paz no puede reducirse a la simpleza de negociar la entrega de unas armas, ni al regreso a la vida corriente de unos insurrectos. Ella involucra el compromiso de la búsqueda de soluciones a los fenómenos que condujeron al conflicto. En Colombia significaría el camino hacia un ánimo de reformas que invaliden el hambre, el analfabetismo, la insalubridad, la falta de vivienda, en fin, a todos esos malestares colectivos que encuentran su causa en las características de la propiedad sobre la tierra y el capital, hoy en manos de terratenientes y monopolistas sólo interesados en acrecentar riqueza y poder. La profunda desigualdad económica de los grupos sociales facilita el camino a la miseria de las masas, al desempleo, a la deformación democrática, a la inflación, a la inseguridad, al delito o, en otras palabras, a la ausencia de la paz (Consuegra, 2002A: 80).

Esto es precisamente lo que debemos tener en cuenta en el actual proceso. Infortunadamente las preocupaciones que difunden los medios de comunicación masiva tienen que ver básicamente con entrega de armas y con cárcel, pero esa no es la paz, como bien lo había dicho consuegra. Vivir en paz es vivir con un modo de vida que no solo garantice los mínimos para mantenerse vivo -lo que no se cumple hoy día, porque muchos campesinos están en riesgo de morir de hambresino que se debe contar con cierto nivel de bienvivir. No hay que olvidar que lo que se firma en La Habana no es la paz sino el fin de la expresión militar del conflicto entre la guerrilla y el gobierno, pero el conflicto permanece en múltiples formas. Es decir, la paz hay que tejerla en los territorios empezando por garantizar a cada familia campesina la cantidad de tierra suficiente para que pueda proporcionarse una vida digna. Por ejemplo, los minifundistas de Nariño tienen en promedio un tercio de hectárea de terreno, superficie a todas luces insuficiente para unas condiciones mínimas de vida. Este tema se encuentra desarrollado en el punto uno de los acuerdos de La Habana, pero por ahora está en el papel, lo cual es ya muy importante, pero falta hacerlo realidad en el territorio.

Insistió el maestro, igual que lo había hecho Antonio García, en no recibir acríticamente las teorías foráneas y aplicarlas a nuestra realidad, siendo esta diferente a los contextos en los cuales dicha teoría fue elaborada. Al respecto, dice el maestro:

No estudiamos nuestra realidad para deducir conclusiones sino que nos limitamos a leer los textos extranjeros de acuerdo con la alineación que nos corresponde: Si estamos dentro de las líneas del capitalismo, toda nuestra formación es a través de los autores norteamericanos o europeos, y si estamos en la línea del socialismo, todavía peor (Consuegra, 2002B: 8).

Infortunadamente, esto es precisamente lo que se hace, en donde menos debería hacerse, en la mayor parte de los programas universitarios de Economía. Basta ver los programas de las asignaturas, particularmente las de la ortodoxia, para ver 
casi todos los textos utilizados han sido traducidos sobre todo del inglés. En las asignaturas relacionadas con el marxismo, el panorama es ligeramente diferente; ejemplo de ello es el texto del propio Consuegra: Apuntes de Economía política, publicado en 1963 y mi texto en la materia: Economía Política. Una propuesta metodológica, publicado en 1996. A pesar de los que solo repiten el pensamiento que llega de los centros, en la escuela marxista hemos contado con pensadores originales en América Latina, como el propio Consuegra Higgins y también Antonio García Nossa, José Carlos Mariátegui, Aníbal Ponce, Bolívar Echeverría y otros más. Pero seguimos siendo minoría, frente al dogmatismo gigantesco que campea en las universidades y fuera de ellas.

La invitación del maestro es, por lo tanto, a pensar con cabeza propia: Mientras nosotros no entremos por cuenta propia a indagar nuestros problemas y a formular nuestros planteamientos teóricos para dar respuesta a todas las diferencias, a todos los problemas del subdesarrollo y la dependencia, no podemos salir adelante (Consuegra, 2002: 21).

Con la caída de la Unión Soviética, desaparecieron en América Latina los manuales de marxismo producidos por el Partido Comunista de la Unión Soviética, PCUS, que tenían un carácter bastante dogmático e influyeron negativamente en muchos científicos sociales latinoamericanos. Hoy contamos con importantes pensadores independientes, tanto marxistas como no marxistas, son los casos de Pablo Guadarrama, Néstor Kohan, Atilio Borón, Renán Vega Cantor, Arturo Suárez, Julio Silva Colmenares, Eduardo Gudynas, Isabel Rauber y muchos y muchas más. Y no solamente en el pensamiento, sino también en las transformaciones sociales prácticas, aparece la originalidad. Son los casos de Bolivia, Venezuela y Ecuador; también Cuba, después de la caída de la URSS, ha iniciado procesos originales. Todos estos procesos son revolucionarios a su manera. Ya nos enseñó Consuegra que lo original es por sí mismo revolucionario y valioso (Consuegra, 2002C: 58).

Otro de los aportes importantes del maestro Consuegra tiene que ver con su investigación del pensamiento social y económico de Colombia y de América Latina, no solo en su presente sino, especialmente, en su pasado. Con esa investigación demuestra que muchos de los conocimientos actuales o recientes ya eran planteados y criticados desde tiempos remotos. Nos comenta el maestro como:

La toma de conciencia del valor de lo nuestro y la duda de lo extraño, sea cual fuese su vestimenta, involucra sus ventajas. Hay en la historia de estos territorios aledaños a Cartagena un pasaje que relata Bartolomé de las Casas en su Historia de las Indias: "Yo requerí, le hizo saber Anciso al cronista, de parte del rey de Castilla, a dos caciques de estos del Cenú, que fuesen del rey de Castilla, y que les hacía saber cómo había un solo Dios... y que éste había venido al mundo y había dejado en su lugar a San Pedro... y éste al santo padre, quien como Señor del Universo, había hecho merced de toda aquella tierra de las Indias y del Cenú al rey de Castilla, y que por virtud de aquella merced, les requería que dejasen aquella tierra, pues les pertenecía; y que si quisiesen vivir en ella, como se estaban, que le diesen la obediencia...".

A la perorata del intruso, aquellos exponentes de la dignidad respondieron: "El Papa suyo debía estar borracho cuando lo hizo, pues daba lo que 
no era suyo, y que el rey, que pedía y tomaba la merced, debía ser algún loco, pues pedía lo que era de otros, y dijeron que ellos eran señores de su tierra y que no había menester otro señor” (Consuegra, 2002C: 58-59).

Es bueno anotar que esa claridad y dignidad de nuestros ancestros no se conserva de la misma manera, tal vez los caciques Cenú no habrían aceptado las imposiciones de las instituciones financieras internacionales, tipo Banco Mundial y Fondo Monetario Internacional, como sí lo hacen nuestros gobernantes modernos. Las razones de que no es adecuado para América Latina copiar sus políticas de otros países, las vemos en la siguiente cita del maestro:

Lo que ha sido o es bueno para la economía de un país o de una región necesariamente no tiene que dar los mismos resultados en otras, mucho menos cuando en la correlación las ventajas fueron o son aprovechadas por una de las partes. Si, por ejemplo, el sistema de producción capitalista impuesto en América Latina engendró la dependencia y el subdesarrollo, todo lo que siga haciéndose a través de sus recomendaciones y teorías sólo servirá para alimentar el proceso del subdesarrollo y la dependencia. Las crisis, que en estos países se muestran a la orden del día, son testimonios elocuentes de dichos supuestos (Consuegra, 2002D: 112).

Si bien, en materia de pensamiento, como lo anoté antes, hay signos alentadores, en materia de políticas de Estado también hay buenos ejemplos, pero aún queda mucho por hacer en nuestro subcontinente. El caso colombiano es un ejemplo claro de políticas económicas dictadas por los países del centro del sistema-mundo capitalista. La exigencia de una teoría propia no es tímida sino una exigencia radical, plantea que elaboremos una Economía Política. Veamos:

América Latina necesita y exige su propia Economía Política. Y el compromiso de sus investigadores debe continuar siendo con la formulación de los enunciados para sus estrategias, sea cual fuese el orden económico imperante.

Sin embargo, la verdad sea dicha, por la complejidad de la dependencia, los profesores de Economía Política, al lado de su pretendida ideología, la convierten en apologética para recitar en las clases los conceptos aprendidos en los manuales escritos en Norteamérica, Unión Soviética, Europa o Asia. Y más aún, desprecian o califican, con el lema de turno, a los que se empeñan en reclamar creación y autenticidad. Es tan grosera la actitud de algunos divulgadores alineados que a veces se viene a la memoria la ironía del genial novelista. Porque, alguna vez, refiriéndose a la literatura, Balzac sentenció: "No inventes; te tomarán por loco o criminal. Copia, sé dócil y vivirás feliz como todo idiota”. Y, para el caso de la ciencia social, también se podría comentar: Si investigas, formulas o creas, te tomarán por revisionista y te despreciarán; repite, recita y traga entero, y vivirás feliz como los idiotas de las sectas (Consuegra, 2002D: 113).

$\mathrm{Su}$ idea es que la originalidad es necesaria, igual en el capitalismo que en el socialismo, particularmente en este caso la historia le ha dado plenamente la razón al maestro. Particularmente lo que se ha dado en llamar en América Latina el 
Socialismo del Siglo XXI requiere pensamiento original, sobre este camino no hay nada hecho lo cual obliga a recordar y llevar a la práctica los versos de Machado: caminante no hay camino/ se hace camino al andar. Es verdad que el pensamiento propio sigue siendo patrimonio de minorías, sobre todo en Colombia, pero el grupo de quienes intentamos pensar con cabeza propia crece cada día. La enseñanza de la Economía se haya en una profunda y saludable discusión mundial, que debemos aprovechar para lograr cambios de fondo. Es una crisis de la cual puede salir algo bueno si sabemos aprovecharla; es muy positivo también el hecho de que la discusión haya sido iniciada por los estudiantes. En el año 2011, al calor del movimiento OcupyWall Street, un grupo de estudiantes de Economía de la Universidad Harvard abandonó su aula de clase y le dirigió una carta abierta a su profesor Gregory Mankiw, uno de los profesores más connotados de esta universidad, explicando cuál era la razón de su protesta. En la carta dicen: Hoy, nos estamos saliendo de su clase, (debido al) sesgo inherente a este curso (...) que adopta una determinada y limitada visión de la ciencia económica, que perpetúa (...) la desigualdad económica en nuestra sociedad. A partir de entonces se ha abierto una amplia discusión en el ámbito internacional, donde estudiantes y docentes de Economía expresan su descontento y proponen alternativas. Voy a referir solo otros dos casos. El primero es el llamamiento por una enseñanza pluralista de la Economía, que hicieron 42 asociaciones de estudiantes de economía de 19 países, donde dicen lo siguiente:

Creemos que es hora de reconsiderar la manera en que se enseña la economía. Estamos insatisfechos con el empobrecimiento progresivo del plan de estudios que ha tenido lugar a lo largo del último par de décadas. Esta falta de diversidad intelectual no sólo perjudica a la educación y a la investigación, sino que limita nuestra capacidad para enfrentarnos a los retos del siglo veintiuno -desde la estabilidad financiera hasta la seguridad alimentaria y el cambio climático-...

....El segundo caso que quiero compartir es lo que afirma la Economista Alicia Puyana, en su ponencia de ingreso a la Academia Colombiana de Ciencias Económica. Dicha ponencia lleva por título De la gran depresión a la gran recesión: los avatares de la Teoría Económica y de la Economía. Puyana plantea en su ponencia lo siguiente: El limitar la teoría macroeconómica a modelar solo lo que se puede sostener con los fundamentos microeconómicos del agente representativo, condujo al predominio de la econometría sobre teoría económica y a desviaciones en su enseñanza, que despertaron inquietud años antes de la crisis (Puyana, 2013: 2).

Creo que la crisis mundial trae buenas noticias en el sentido de la enseñanza de la Economía, como lo planteó con mucha vehemencia el maestro, en el sentido de no obligar la realidad latinoamericana a someterse a las teorías importadas, sino partir de la realidad y elaborar la teoría que su comprensión exija.

Otro aspecto importante de los que fueron preocupación del maestro Consuegra, se relaciona, por una parte, con la importancia de la organización social anterior a la llegada de los europeos y, por otra, con los aportes teóricos autóctonos que son reciclados en los llamados países desarrollados y que luego regresan de nuevo como si se tratara de una creación extranjera. Veamos, al respecto un par de ejemplos. En cuanto a lo primero, dice el maestro: 
La economía indígena era ejemplar en su tiempo. Los autores destacan la producción especializada de acuerdo a las posibilidades de las regiones y tribus que condicionaban el intercambio. La sal, el algodón, el oro, el pescado, el maíz, etc., fueron motivo de trueque simple, o de mercados más amplios en las ferias periódicas. Para entonces el trabajo lo era todo y la propiedad comunal regía el destino del pueblo. No se conocía el hambre, y aunque ciertas formas de individualidad se iniciaban en el campo político, la sencillez y equidad predominantes respondían a una orientación particular en el manejo de la actividad económica (Consuegra, 2002E: 31-32).

\section{Y, en otra obra agrega:}

El maíz, con la yuca y la papa, alimentaba a toda la población autóctona de la América. Los indios, como ninguna otra raza, valoraban la importancia de su grano. En sus hermosas leyendas, dice Diego López, le conceden la gracia de ser la materia prima en la creación del hombre. Los huastecos lo llamaban ToNacayo, que quiere decir nuestra carne. Y Linneo lo registra así, teniendo en cuenta que en las islas del Caribe su nombre es mahis que significa causa de la vida. Cinco mil quinientos años antes de llegar los conquistadores a imponer otras costumbres, el maíz se cultivaba en esta tierra. Aquí había nacido de manera espontánea en su ambiente natural y propicio. Pero el dominio colonial del pasado obligó al consumo del trigo traído de Europa (Consuegra, 2002F: 94).

Hay algunas afirmaciones de Consuegra en estas citas, que son de mucha importancia. Nos dice que el trabajo lo era todo; es decir no había nadie que viviera del trabajo de otro, este es precisamente el sueño de lo que debe venir después del Capitalismo. Dice también que no se conocía el hambre; era una sociedad muy distinta a la actual, llamada de la abundancia, donde uno de cada siete habitantes del planeta está en riesgo de morir de hambre. A diferencia de la leyenda judía, según la cual el primer hombre fue hecho de barro, los indios del Caribe decían que el hombre era de maíz, por eso el nombre del grano era mahis, que quiere decir causa de la vida.

Muchos pensadores consideran que las pistas para una sociedad poscapitalista se deben buscar en las sociedades primitivas, cuando aún no existía la propiedad privada. Entre esos pensadores se encuentra Carlos Marx, al final de su vida él se dedicó a estudiar los escritores que investigaban las comunidades primitivas y sus apuntes sobre el tema fueron publicados más de 100 años después de su muerte, con el nombre de Apuntes etnológicos.

Lawrence Krader quien organizó los apuntes y escribió la introducción al libro, dice lo siguiente:

Marx vio en esta anagnórisis el signo de que el hombre moderno posee en su conducta un componente arcaico comunal, que mantiene arraigado en su ser social un factor democrático e igualitario. La comparación con el pasado era para él algo básico a la hora de criticar la actual situación civilizada (Krader, 1988: 9). 
Anagnórisis es una palabra del griego antiguo que significa reconocimiento de sí mismo o descubrimiento de un componente importante de su vida que había permanecido oculto. Marx consideró que el capitalismo era una especie paréntesis en la historia humana. Seguramente si la especie humana logra superar este paréntesis, en un futuro lejano, cuando los humanos puedan rescatar su esencia de humanos, que no es ni la competitividad ni la acumulación de dinero, clasificarán el capitalismo como uno de sus malos recuerdos. Hay razones para pensar que lo que nos ofrece hoy el sistema-mundo capitalista no es como para enorgullecer a nadie. El Economista Georgescu-Roegen decía que si viniera a la tierra un extraterrestre inteligente lo que más tendría dificultades para entender sería por qué entre los terrícolas el que más trabaja recibe menos a cambio, mientras que el que más recibe trabaja menos. Yo digo que ese extraterrestre no podría comprender por qué las fronteras de los países están abiertas para el tránsito libre de capitales y mercancías, pero se levantan muros y alambradas para impedir el tránsito de las personas.

Uno de los problemas que aquejan a la economía colombiana está relacionado con el comercio exterior y todo lo que tiene que ver con los tratados de libre comercio. Las autoridades económicas no pueden entender, por ejemplo, por qué la subida del precio del dólar no se expresó de inmediato en un incremento de las exportaciones, como sería de esperar según el manual. La razón para este fenómeno es que el sometimiento de la economía colombiana a la competencia con economías más fuertes y subsidiadas llevó a una drástica disminución de la industria y la agricultura nacionales. Cuando la devaluación del peso debía impulsar las exportaciones, ya no había qué exportar. Sobre este aspecto, también el maestro nos aconseja, entre otras fuentes, acudir a los aportes de los pensadores de nuestro pasado; en ellos encontramos argumentos para la defensa. Por una parte tenemos a Bolívar:

En plena lucha liberadora, el genio de Bolívar señala los caminos de la autenticidad. Sus ideas económicas determinan pautas. Tal vez su mayor aporte se desprende de sus conceptos sobre la integración. Ante todo Bolívar expone una estrategia defensiva que corresponde a todo un proceso histórico. Es el signo del rasgo latinoamericano, en cuyo suelo se ensaña la presencia del expoliador extranjero de todos los tiempos (Consuegra, 2002E: 35).

Por otra parte, Castillo y Rada, contemporáneo de Bolívar, dice, según cita de Consuegra:

Castillo y Rada hace del razonar proteccionista un instrumento adecuado para el desarrollo, más allá del simple beneficio fiscal. Sus palabras son: "Las aduanas no sólo son fuente de una renta cuantiosa, sino también medios poderosos de fomentar la agricultura, las manufacturas y el comercio". Con este enfoque se dejaba a un lado la especialización internacional del trabajo que los voceros del sector comercial, así como los idiotas útiles del liberalismo de todos los tiempos, no han dejado de acoger para gracia del subdesarrollo y la dependencia (Consuegra, 2002C: 52). 
Ideas semejantes se encuentran en el alemán Federico List, en un libro publicado en 1841, él dice:

...fue, entonces, evidente para mí, que entre dos naciones muy adelantadas, la libre competencia sólo puede influir de modo benéfico para ambas cuando las dos se encuentran en el mismo nivel de progreso industrial, y que una nación rezagada... debe en primer término poner en tensión todas sus fuerzas para llegar a competir después con las naciones más adelantadas (List, 1979: 4).

Lo que está diciendo List es que al poner a competir a dos países con distintos niveles de desarrollo, solo se va a beneficiar el país más desarrollado. Y cuando alguien quiere buscar antecedentes de la teoría proteccionista, como lo hacen al hablar de Raúl Prebisch, siempre hacen alusión a List, nadie se refiere a Bolívar o a Castillo y Rada, habiendo dicho estos lo mismo que el alemán, muchos años antes que este. La necesidad de defender la economía colombiana de la competencia de los países más desarrollados, fue uno de los planteamientos centrales de Antonio García Nossa, esa es la razón para que uno de sus principales libros Bases de economía contemporánea tuviera como subtítulo Elementos para una economía de la defensa. Ese principio fue también un planteamiento central de José Consuegra. La historia les ha dado la razón, con los procesos de desmonte de la industria y de la agricultura colombianas, a causa de los tratados de libre comercio. El principio que se plantea es que el fundamento del desarrollo industrial y agrario de un país y, particularmente, en los países periféricos, mal llamados subdesarrollados es el mercado interno.

No solo en el campo de la protección de la economía interna encontramos teorías originales en el pensamiento de América Latina. Incluso en teoría monetaria encontramos planteamientos teóricos muy antiguos en nuestro medio. Consuegra nos recuerda el caso de Matienzo, en la época de la colonia. Dice el maestro:

Por ejemplo, en el campo de análisis de los fenómenos monetarios, los investigadores latinoamericanos han hecho saber que la teoría cuantitativa fue expuesta en este continente doscientos años antes de que lo hicieran los economistas europeos. También el juicio estructural de la escuela cepalina, así como el enfoque ofertaprecio que me permití presentar en el libro Teoría de la inflación, el interés y los salarios, forman parte de la aportación latinoamericana (Consuegra, 2002: 183). Por ejemplo, Juan de Matienzo y los otros analistas, en sus observaciones en los sitios cercanos de las minas de oro y plata que jamás hasta entonces el mundo había conocido, pueden apreciar que los productos adquieren allí precios superiores a los de otras partes. Igual sucede en Sevilla, donde llegan los metales preciosos de las Indias, con relación a otras ciudades de España. De ese acontecer deducen la teoría cuantitativa de la moneda y el fenómeno de la inflación (Consuegra, 2002G: 186).

Es verdad que ni el maestro ni yo compartimos la teoría cuantitativa del precio, pero es una teoría importante, desarrollada luego por muchos teóricos europeos.

Finalmente quiero traer una cita de uno de los libros más importantes del maestro: Teoría de la inflación, el interés y los salarios. En esta obra el maestro tiene planteamientos originales, relacionados con la Economía Política Marxista, particularmente sobre la teoría del dinero. A diferencia de la teoría cuantitativa 
anteriormente mencionada, cuyo primer teórico fue Matienzo, al decir de Oreste Popescu, Marx consideraba que el precio es la expresión dineraria del valor de las mercancías, el cual a su vez depende del trabajo socialmente necesario para su producción. La cantidad de dinero, necesario para la circulación de las mercancías, está determinada por el volumen de mercancías y sus precios y no al contrario. Es decir, la cantidad de dinero no determina los precios, sino al contrario, la cantidad de dinero no es causa sino efecto. Consuegra critica en su libro, como en otras obras, a los manuales soviéticos de Economía porque terminan pareciéndose más a la teoría cuantitativa del precio que a la teoría del valor trabajo de Marx. Sobre todo en la época actual de economía monopólica, la libre competencia ha dejado de existir hace mucho rato, los precios son hoy fijados voluntariamente por los monopolios y las emisiones de papel moneda son posteriores a la fijación de dichos precios. Consuegra denomina su teoría de la inflación como Oferta precio. Traigo una cita del libro mencionado, que expresa a cabalidad el contenido de la obra:

\begin{abstract}
Más que nunca, en nuestros días, el análisis de Marx tiene una comprobación universal. En la etapa actual, con una economía total de mercado imperfecto, manejada por los grandes monopolios internacionales, ahora llamados empresas multinacionales, y, en lo interno, representada por la concentración latifundista, la actividad oficial del capitalismo de estado, etc., los precios son simples marionetas manejadas por los oferentes. Como siempre ha sucedido, pero ahora pudiéndose apreciar sin que se facilite la confusión y el engaño, la suma total de los precios es la que determina y regula la cantidad de dinero necesaria para el cambio, dado un ritmo en la circulación de la moneda (Consuegra, 1997: 152-153).
\end{abstract}

\title{
CONCLUSIONES
}

Para terminar, quiero felicitar a la Universidad Simón Bolívar y a la Familia Bolivariana por mantener viva la Cátedra Latinoamericana José Consuegra Higgins, que nos permite reunirnos y dialogar sobre el pensamiento del maestro y sobre el Pensamiento Propio. Quiero hacer dos propuestas a la Universidad y a la familia Bolívar:

1. La obra que más estudió el maestro Consuegra fue la de Carlos Marx, particularmente El capital. Él contaba que cuando conoció la existencia de esta obra la compró con la plata que tenía para el arriendo en Bogotá y todos sus libros son prueba de su dominio del pensador alemán. En el año 2017 se cumplirán 150 años de la primera edición del tomo I de esta obra y ya hemos iniciado, con el apoyo de varias universidades -Nacional, Distrital, Libre, De Nariñola realización de actividades académicas conmemorativas; quiero invitar a la Universidad Simón Bolívar a unirse a estas conmemoraciones.

2. Creo también que el Pensamiento Propio merece un trabajo más permanente, por ejemplo un posgrado en Pensamiento Propio. Y... si ese posgrado no lo hace la Universidad Simón Bolívar, ¿entonces quién? 


\section{BIBLIOGRAFÍA}

1. AMIN, Samir (2009). ¿Salir de la crisis del capitalismo o salir del capitalismo en crisis? Disponible en www.google.com.co/webhp?sourceid=chromeinstant\&ion.PDF (consultado, nov. 10-15).

2. BAUMAN, Zygmunt (2006). Modernidad líquida. Fondo de Cultura Económica, Buenos Aires.

3. Carta abierta a Mankiw (2011). Disponible en www.google.com.co/webhp?ie=UTF-8\&rct=j\#q=una+carta+abierta+a+gregory+mankiw +en+espa\%C3\%B10l

4. CONSUEGRA HIGGINS, José (1997). Teoría de la inflación, el interés y los salarios. Plaza \& Janés, Bogotá.

5. CONSUEGRA, José (2002). Brevezas literarias. En Obras Completas, tomo 1, Temas económicos y sociales. Editorial Mejoras, Barranquilla.

6. CONSUEGRA, José (2002A) Otros comentarios sobre personajes del Pensamiento Social Colombiano. En Obras Completas, tomo 1, Temas económicos y sociales. Editorial Mejoras, Barranquilla.

7. CONSUEGRA, José (2002B). El pensamiento económico latinoamericano contemporáneo. En Obras Completas, tomo 1, Temas económicos y sociales. Editorial Mejoras, Barranquilla.

8. CONSUEGRA, José (2002C). Ideas económicas de cinco cartageneros. En Obras Completas, tomo 1, Temas económicos y sociales. Editorial Mejoras, Barranquilla.

9. CONSUEGRA, José (2002D). Por una teoría económica propia. En Obras Completas, tomo 1, Temas económicos y sociales. Editorial Mejoras, Barranquilla.

10. CONSUEGRA, José (2002E). El pensamiento económico colombiano. En Obras Completas, tomo 1, Temas económicos y sociales. Editorial Mejoras, Barranquilla.

11. CONSUEGRA, José (2002F). El pensamiento social latinoamericano. En Obras Completas, tomo 1, Temas económicos y sociales. Editorial Mejoras, Barranquilla.

12. CONSUEGRA, José (2002G). Origen latinoamericano de las teorías de la inflación. En Obras Completas, tomo 2, Temas económicos y sociales. Editorial Mejoras, Barranquilla.

13. KRADER, Lawrence (1988). Los apuntes etnológicos de Karl Marx. Siglo Veintiuno Editores, Madrid.

14. LIST, Federico (1979). Sistema Nacional de Economía Política. Fondo de Cultura Económica, México, D.F.

15. PIKETTY, Thomas (2014). El capital en el siglo XXI. Fondo de Cultura Económica, Bogotá.

16. PUYANA, Alicia (2013). De la gran depresión a la gran recesión: los avatares de la teoría económica. Disponible en: www.google.com.co/ webhp?ie=UTF-8\&rct=j\#q=alicia +puyana+De+la+gran+depresi\%C3\%B3n+a+la+gran+recesi\%C3\%B3n (Consultado, nov. 10-15).

17. SABOGAL TAMAYO, Julián (2007). José Consuegra Higgins. Abanderado del pensamiento propio. Editorial Universidad Simón Bolívar, Bogotá.

18. SASSEN, Saskia (2015). Expulsiones. Brutalidad y complejidad en la Economía Global. Kats Editores, Bogotá. 